\title{
Powerful knowledge and epistemic quality in school mathematics
}

\author{
Brian Hudson* - University of Sussex, UK and Karlstad University, Sweden
}

\begin{abstract}
This article contributes to current debates on progressive, knowledge-based approaches to the curriculum by addressing the question of what it is that students are entitled to learn in school mathematics. From the outset it recognizes progressive arguments that teaching should be reconnected with the emancipatory ambitions of education. In doing so, it takes the notion of powerful knowledge as a starting point, based on what knowledge school students have the right to have access to. In turn, it considers this as a question of epistemic quality. This is elaborated as a concept by drawing on outcomes from a recent study arising from the Developing Mathematical Thinking in the Primary Classroom (DMTPC) project. This concept is founded on the analysis of a distinction between mathematical fallibilism, based on a heuristic view of mathematics as a human activity, and mathematical fundamentalism, which reflects an authoritarian view of the subject as being infallible, absolutist and irrefutable. The relation between powerful knowledge and epistemic quality is considered further by framing it within a sociological theory of knowledge. This helps to highlight a further distinction between knowing that and knowing how, which is used to illustrate examples of high and low epistemic quality in school mathematics. The first example of high epistemic quality is drawn from the DMTPC project. The second example is of low epistemic quality and comes from the highly promoted Core Knowledge Foundation that has recently been imported into English schools from the USA. Finally, the article considers the role of teachers as curriculum makers at the classroom level where curriculum and pedagogy effectively merge. In conclusion, the implications for both policy and practice are considered, in particular proposals are made in relation to the role and place of subject didactics in teaching and teacher education.
\end{abstract}

Keywords: powerful knowledge; epistemic quality; mathematical thinking; know how; subject didactics

\section{Introduction}

What is curriculum as we now understand the word? ... It is not a syllabus - a mere list of content to be covered - nor even is it what German speakers would call a Lehrplan ... Nor is it in our understanding of a list of objectives. Let me claim that it is a symbolic or meaningful object, like Shakespeare's first folio, not like a lawnmower; like the pieces and board of chess, not like an apple tree. It has a physical existence but also a meaning incarnate in words or pictures or sound or games or whatever ... by virtue of their meaningfulness curricula are not simply means to improve teaching but are expressions of ideas to improve teachers. Of 
course, they have day-to-day instructional utility: cathedrals must keep the rain out .... (Stenhouse, 1980: 40)

This article contributes to current debates on progressive, knowledge-based approaches to the curriculum (Lambert and Biddulph, 2015) by addressing the question of what students are entitled to learn in school mathematics. It recognizes the progressive argument presented by Biesta (2017: 3) that teaching does not necessarily have to been seen as an act of control, but can be understood and 'reconnected with the emancipatory ambitions of education'. In particular, it recognizes the critique made by Biesta (2010) that the international turn towards generic, skills-based curricula has resulted in the 'learnification' of education, which has undermined teaching and the role of the teacher. As argued further by Biesta (2012), the point of education is never simply that children learn, but that they learn something for a particular purpose and that they learn this from someone. The article builds on the argument presented by Lambert and Biddulph (2015) that the UK government's recent policy shift to restore 'a core of essential knowledge' in England can be seen as a direct response to the perception that the turn towards generic skills had undermined disciplinary rigour in schools. Furthermore, it also recognizes the recent policy of conservative restoration to be 'an inadequate response to Biesta's critique of a dysfunctional curriculum' (ibid.: 211). This is especially so in relation to school mathematics, the nature of which is so often simply taken as given and is not questioned.

The notion of powerful knowledge (Young, 2013) is the starting point and is based on what knowledge school students are entitled to have access to. It considers this as a question of epistemic quality which is elaborated as a concept by drawing on the outcomes of a recent empirical study arising from the Developing Mathematical Thinking in the Primary Classroom (DMTPC) project (Hudson, 2016a, 2017; Hudson et al., 2015). The latter concept is founded on a distinction between mathematical fallibilism, based on a heuristic view of mathematics as a human activity, and mathematical fundamentalism, which reflects an authoritarian view of the subject as being infallible, absolutist and irrefutable. The relation between powerful knowledge and epistemic quality is developed further by framing it within a sociological theory of knowledge. In considering the role of curriculum theory in relation to 'access to knowledge', Young (2013: 103) argues that the neglect of this role is at the heart of 'the crisis' referred to in the title of his article 'Overcoming the crisis in curriculum theory: $A$ knowledge-based approach'. He argues for the need to address epistemological issues concerning questions of the truth, the reliability of different forms of knowledge and how such issues have both philosophical and sociological dimensions. Following this line of argument, the idea of epistemic access (Morrow, 2009) is seen to be of particular significance. In particular, Morrow argues that our task as curriculum theorists and teachers is to develop curriculum principles that maximize the chances that all pupils will have access to the best knowledge available in any field of study they engage in (ibid.). Further, by drawing on a sociological theory of knowledge (Muller, 2016), an important distinction is highlighted between knowing that and knowing how. This distinction is used subsequently to illustrate how mathematical thinking and associated processes of creative reasoning are central to such know how. This distinction is then used to illustrate examples of high and low epistemic quality in school mathematics. The first example is of high epistemic quality and is drawn from the DMTPC project. This illustrates how mathematical thinking and the associated processes of creative reasoning are central to such know how in school mathematics. The second example is of low epistemic quality and comes from the highly promoted Core Knowledge 
Foundation which has recently been imported into English schools from the USA. This illustrates an overemphasis on practice, presents a fragmented view of the subject and reduces standard procedures simply to rule following. Finally, the article considers the role of teachers as curriculum makers in these processes where 'curriculum making is in effect curriculum thinking in practical action taking on a trinity of educational practice' of subject, child and teacher (Lambert and Biddulph, 2015: 217). This happens at the classroom level where curriculum and pedagogy effectively merge. In conclusion, the implications for both policy and practice are considered in particular proposals made in relation to the role and place of subject didactics in teaching and teacher education.

\section{Powerful knowledge}

As part of the discussion on knowledge and the future school, Young (2014) refers to a 'three futures' approach to the curriculum, based on his earlier work with Muller (Young and Muller, 2010). The three models, described as Future 1, Future 2 and Future 3, are used to think about where the present curriculum has come from and what it might look like in the future. Future 1 refers to the curriculum inherited by secondary schools from the nineteenth century, against which, it is noted, many teachers reacted from the 1970 s onwards, in particular those who taught slow or disadvantaged learners. Further, it is symbolized by a typical curriculum from the grammar and public schools, which formed the basis of the first National Curriculum for England and Wales established in 1988 and was presented as a curriculum for all. Put simply, under a Future 1 scenario, knowledge is treated as largely given and established on the basis of tradition. It also offers high achieving students a route to the leading universities in the country. Accordingly, a Future 1 curriculum is seen as an extended version of the past.

The Future 2 curriculum gradually emerged over a period of time in response to the rigidity of Future 1 and in response, initially, to the needs of lower achievers. Curriculum boundaries between school subjects were weakened in order to open up new forms of interdisciplinary studies, and the insulation of subjects from everyday knowledge was also weakened as the curriculum was extended to include leisure, sports and other community interests. These changes were made as part of policies of social inclusion and widening participation. In parallel, there was a weakening of the boundaries between the worlds of school and work as an increasingly vocational curriculum was introduced for lower achieving students, many of whom were from disadvantaged backgrounds. This change was part of 'an increasingly instrumental view that education was a means to an end - usually expressed as the expectation of future employment' (ibid.: 60). The changes made by the coalition government (201015) can be seen as a return to a Future 1 curriculum for all.

The argument for an alternative Future 3 scenario is presented on the basis that 'both Future 1 and 2 views of knowledge are partly right but fundamentally mistaken' (ibid.: 65). It points towards an alternative curriculum for the future based on an idea of knowledge that differs from both Future 1 and Future 2 in a number of ways. First, it explicitly locates knowledge within the specialist communities of researchers in different fields and consequently does not treat knowledge as given, but as fallible and open to challenge through dialogue and debate within the specialist communities. Unlike the openness of knowledge assumed by Future 2, knowledge under Future 3 is bounded by the epistemic rules of the particular specialist communities. It follows that Future 3 treats subjects as the most reliable tools that have been developed for enabling students to acquire knowledge and make sense of the world. 
The idea of 'powerful knowledge', which was introduced by Young (2009), is a curriculum principle that underpins the Future 3 model. In discussing the question of what knowledge school students are entitled to have access to, he argues that 'in all fields of enquiry, there is better knowledge, more reliable knowledge, knowledge nearer the truth about the world we live in and to what it is to be human' (Young, 2013: 107). The concept is based on two key characteristics expressed in the form of boundaries. First, this knowledge is specialized both in terms of how it is produced and transmitted. This specialization is expressed through the boundaries between disciplines and subjects which define their focus and objects of study. Secondly, it is differentiated from the experiences that pupils bring to school or older learners bring to college or university, which is expressed in the conceptual boundaries between school and everyday knowledge (Young, 2013).

Accordingly, this article takes the concept of 'powerful knowledge' as its starting point and considers this as a question of 'epistemic quality' in school mathematics. In the next section this is elaborated as a concept by drawing on the outcomes from a recent study arising from the DMTPC project.

\section{Epistemic quality in school mathematics}

The notion of epistemic quality in school mathematics was first discussed in Hudson et al. (2015) who drew on the outcomes of a research study, the Developing Mathematical Thinking in the Primary Classroom (DMTPC) project. The background for this initiative was the Scottish Curriculum for Excellence reform which, in turn, was located within the wider international review of the quality and equity of education outcomes conducted by the Organisation for Economic Co-operation and Development (OECD, 2007). The DMTPC project was funded by the Scottish government during 2010-12 and involved a group of practising teachers $(n=24)$ who were all participants in a newly developed Master's course that had been designed with the aim of promoting the development of mathematical thinking in the primary classroom. The course of study was structured around three key questions, two core texts and an action research project. The key questions were:

1. What is mathematics?

2. What is mathematical thinking?

3. What is good mathematics teaching?

The research questions that guided the study focused on the teachers' confidence, competence, attitudes and beliefs in relation to mathematics, and their expectations and experiences of the impact on pupil learning arising from this course. Empirical data were drawn from pre- and post-course surveys, interviews and the discussion forums in the online environment. Findings from this study highlight that the course had a transformational and emancipatory impact on these teachers. They also highlight how the 'framing' of particular aspects of the curriculum had an oppressive impact on learners in ways that suppressed their creativity and limited their exercise of autonomy. Further, they point to the manner in which several of these teachers had themselves as pupils experienced mathematics as a school subject in very negative ways, involving high levels of 'symbolic violence' and of being 'labelled'. In particular, the teachers had some very powerful responses to reading one of the core texts entitled The Elephant in the Classroom, in which the author writes:

I have called this book 'The elephant in the classroom' because there is often a very large elephant standing in the corner of maths classrooms. 
The elephant, or the common idea that is extremely harmful to children, is the belief that success in mathematics is a sign of general intelligence and that some people can do maths and some can't. Even maths teachers (the not so good ones) often think that their job is to sort out those who can do maths from those who can't. This idea is completely wrong and this is why. In many maths classrooms a very narrow subject is taught to children, that is nothing like the maths of the world or the maths that mathematicians use. This narrow subject involves copying methods that teachers demonstrate and reproducing them accurately over and over again. Of course, very few people are good at working in such a narrow way, and usually everyone knows which people are good at it and which people are not. But this narrow subject is not mathematics, it is a strange mutated version of the subject that is taught in schools. When the real mathematics is taught instead - the whole subject that involves problem solving, creating ideas and representations, exploring puzzles, discussing methods and many different ways of working, then many more people are successful. (Boaler, 2009: 2)

This process of mutation is seen as a transformation process and, in particular, as an example of 'didactic transposition' as outlined by Chevallard (Chevallard and Johsua, 1991; Chevallard, 2007). The concept of didactic transposition arises from research in the field of French didactics in particular and builds on the seminal work of Brousseau (1997) on 'didactic situations' (see also Hudson, 2016b for further discussion). The basic principle underpinning this perspective on learning and teaching is that knowledge is not something to be taken as simply given and to be explained. Rather, it is the case that 'knowledge is potentially encapsulated in situations, and it is in going through those situations that the pupil, or whoever, can learn' (Chevallard, 2007: 132). This view of learning as 'learning from the situation' is a central principle of French didactics which sees knowledge as built up and transformed or transposed in didactic situations. Underpinning this theory is an ecological approach to the social dynamic of knowledge (ibid.). The main point in didactic transposition theory is that it considers knowledge as a changing reality, which adapts to its institutional habitat. Accordingly, in relation to the school context, the knowledge in question is not knowledge for enacting and solving problems in the social contexts in which it was created and where it is used, but instead is transposed into knowledge to be taught and learned. As highlighted by Schneuwly (2011), the concept of didactic transposition is based on the recognition that there is a 'rupture' between daily life and school, and which changes the knowledge profoundly.

The discussion of epistemic quality in mathematics by Hudson et al. (2015) is founded on the analysis of a distinction that is made between mathematical fallibilism, based on a heuristic view of mathematics as a human activity (Lakatos, 1976), and mathematical fundamentalism, which describes the transposed 'mutated' version outlined above. This distinction is seen as a question of 'epistemic quality' in terms of what the students are expected to know, understand and be able to do. Accordingly, consideration of the 'best knowledge' that all pupils will have access to (Morrow, 2009) and/or the 'better knowledge, more reliable knowledge, knowledge nearer the truth' as elaborated by Young (2013: 107), requires that this knowledge needs to be of high epistemic quality. This involves an approach that presents mathematics as fallible, refutable and uncertain, and which promotes critical thinking, creative reasoning, the generation of multiple solutions and of learning from errors and mistakes. In contrast, school mathematics of low epistemic quality is characterized by an approach that 
presents the subject as infallible, authoritarian, dogmatic, absolutist, irrefutable and certain, and also involves rules that follow strict procedures and right or wrong answers.

It is further argued (ibid.) that high epistemic quality is promoted through an approach that is based on assessment for learning, which involves low stakes formative and self-assessment. This is engaging and motivating for individual learners and can create the conditions that lead them to a sense of enjoyment of mathematics and fulfilment in the subject as a creative human activity. In contrast, the excessive pressure from high stakes external testing and inspection, and the associated heavy emphasis on drill and practice, can establish circumstances that degrade the epistemic quality into the mutated form of mathematical fundamentalism described earlier and lead learners of mathematics to experience it as something to be feared and as anxietyinducing, boring, demotivating and alienating from the subject itself.

The central role of creative reasoning is considered further in Hudson (2016a, 2017) and draws on the work of Lithner (2008) who offers a conceptual framework that compares and contrasts creative and imitative reasoning in mathematics that fits with our distinctions (ibid.) made between high and low epistemic quality. With regard to imitative reasoning in mathematics, Lithner (2008) highlights two aspects: memorized reasoning and algorithmic reasoning. Memorized reasoning is seen to fulfil two conditions. First, the strategy choice is founded on recalling a complete answer and, second, the strategy implementation consists only of writing it down. In relation to algorithmic reasoning and with reference to Brousseau (1997: 129), an algorithm is defined as 'a finite sequence of executable instructions that allows one to find a definite result for a given class of problems'. Similarly, algorithmic reasoning fulfils two conditions. First, the strategy choice is to recall a solution algorithm about which the predictive argumentation may be of different kinds but does not necessitate the creation of a new solution. Second, the remaining reasoning parts of the strategy implementation are trivial for the reasoner and only a careless mistake can prevent an answer from being reached. Lithner (2008) also stresses how textbooks and teachers can serve to reinforce such superficial imitative reasoning.

In contrast, creative mathematical reasoning involves novelty, plausibility and mathematical foundation, while creativity is seen as an orientation or disposition towards mathematical activity that can be fostered broadly in school. This perspective is reflected in the US Standards of the National Council of Teachers of Mathematics (NCTM, 2000: 56) which recognizes reasoning and proof as fundamental aspects of mathematics: 'People who reason and think analytically tend to note patterns, structure, or regularities in both real-world situations and symbolic objects; they ask if those patterns are accidental or if they occur for a reason; and they conjecture and prove.' Lithner (2008) argues that such reasoning can have many functions in mathematics, including verification, explanation, systematization, discovery, communication, construction of theory and exploration. This framework provides a specific focus on problem-solving, especially the phases formulated by Pólya (1954) and elaborated by Schoenfeld (1985), which are: reading the task (including noting conditions and goals), analysing (to understand, select perspective and perhaps reformulate), exploring (a broader and less structured search for information), planning, implementing (including evaluation of progress) and verifying.

\section{Developing 'know how' in school mathematics}

In relation to the question of access to education, Young (2013: 115) argues that our task as curriculum theorists and teachers, whatever our politics as citizens, is to develop 
curriculum principles that maximize the chances that all pupils will have epistemic access (Morrow, 2009) - that is to say, access to the best knowledge we have in any field of study they engage in. Furthermore, he argues (ibid.) that the political message of a knowledge-based curriculum is that the inequalities in the distribution of resources must be reduced in order to improve educational opportunities for all. In building on this notion in relation to primary education, du Plooy and Zilindile (2014: 198) relate this to the idea of 'meaningful or expanded' access.

Developing this line of reasoning further by framing it within a sociological theory of knowledge, an important distinction is made (Muller, 2016) between knowing that (or propositional knowledge) and knowing how (or procedural knowledge) and it is argued that every area of the curriculum can be described in these terms. Furthermore, there are two different kinds of 'know how' knowledge that are important for the curriculum - inferential know how and procedural know how. First, with regard to inferential know how, this is about 'knowing how the conceptual knowledge (the 'know that') hangs together, and how to negotiate the epistemic joints that link the various knowledge bits together' (ibid.: 103). Second, in relation to procedural know how, this points to a more risky and uncertain kind of knowledge where the newcomer 'learns how to find out new things, finds out which warrants and tests work under what circumstances, what the tolerances and limits are in real situations, forming new judgements that lead to solutions that work in the world' (ibid.: 103). Furthermore, Winch (2013) also distinguishes a range of practical 'know hows' that are often conflated with 'skills' or 'practical expertise'.

These forms of knowledge are seen to be cumulative in three senses. First, it is argued (ibid.) that the learner must have reasonable mastery of the know that (the conceptual content) before they can begin to grasp how the know how works. Second, the learner must be helped to grasp the inferences and the inferential relations before they will be able to venture into uncertain territory with the procedural know how with any confidence. Third, and most significantly, the various know hows are themselves seen to be nested, that is they also ascend epistemically, which means that they also have features of greater and lesser complexity that must be correctly sequenced in a coherent curriculum.

In exploring the impact on pupil learning arising from the teachers' experiences of being involved in the DMTPC project outlined earlier, a close analysis was made of the written outcomes of the teachers' action research projects and this analysis was developed further by framing it within this sociological theory of knowledge. One of the project reports that was considered most effective was based on the development of a topic-based approach to teaching and learning mathematics on the theme of 'The rainforest', which subsequently became the focus of Hudson's (2015) article. The findings from this analysis highlight the ways in which the children actively engaged in the learning environment based on the Amazon rainforest and also the ways in which the teacher developed the teaching and learning situation by extending the 'epistemic' dimensions of the tasks through the use of the open-ended topic-based approach combined with effective teacher questioning. They also highlight the ways in which the discursive elements of these lessons proved to be a very effective means through which to support the children to engage in the learning environment and to develop mathematical thinking as a part of their developing procedural know how. It was evident from this analysis that children had very differing prior knowledge (including know how) and experiences to bring to the problem-solving elements of the tasks and that, due to their ability to visualize the problems, the mathematics became 
more accessible. This led to an evolution in mathematical thinking, and procedural know how in particular, for all.

\section{Overemphasizing 'knowing that' in school mathematics: Back to Future 1}

With regard to the idea of 'Back to Future 1', Young (2014) outlines the way in which two very different developments, happening at the time around the end of the last Labour government in the UK, took completely opposite views in the argument that 'knowledge' was an elitist notion. The first development was a shift in governmental thinking on education 'away from subjects and knowledge towards an emphasis on learning as an activity' (ibid.: 62). This was characterized by an emphasis on twenty-firstcentury skills or competences such as critical thinking, learning to learn and working with others. It was based on the assumption that young people no longer needed to acquire specific knowledge but that they needed to learn how to manage it. The second development was presented as a radical alternative to Future 2. However, this alternative future looked backwards rather than forwards and did not emerge from faculties of education or teacher unions that are usually seen as the traditional sources of innovative ideas. Rather, this development emerged from think tanks, including Civitas, Reform and Politea, which are completely separate from the wider education community. As a part of this development, 'an almost ready-made solution' was found by the coalition government in 2010 in the work of E.D. Hirsch, in particular in his book Cultural Literacy: What every American needs to know. This work had not previously had any significant influence in the UK but the ideas and associated resources in the form of the Core Knowledge Series was imported from the USA on a significant scale by Civitas. Young (2014) continues by stating that the problem with the government's version of Future 1 is not that it endorses a knowledge-led curriculum but rather that this particular version of knowledge is fixed in historical terms and includes no plans for how it could become a 'curriculum for all'. He also notes that, despite its flaws, this development has opened up a debate about 'knowledge', the key role of school subjects and also how these may or may not relate to university disciplines.

The Core Knowledge website (2018a) provides activities, stories and lesson plans, as well as information about its series of books, What Your Child Needs to Know, for youngsters aged 4 to 11. It indicates that the resources can be used at home and in the classroom, by parents, teachers and home educators, and as 'the perfect study aid for the new National Curriculum'. In this article, attention is given to the mathematics curriculum and questions are raised about the epistemic quality of the mathematical content of what Core Knowledge aims to impart. In particular the content of the text aimed at Year 6 entitled What Your Year 6 Child Needs to Know: Fundamentals of a Good Year 6 Education (Hirsch, 2014) is analysed.

In the introduction to the mathematics section (ibid.: 211), it is claimed that 'success in learning mathematics comes through practice'. Stress is placed on 'a sound grasp of basic facts and an automatic mastery of fundamental operations'. Furthermore, it is claimed that since practice is the secret to mastery, that practice is a prerequisite for more advanced problem-solving. The text continues by re-emphasizing the stress on practice and making claims for its pre-eminence. The stress on practice is reinforced with the statement that 'to learn maths thoroughly, children need to be shown these concepts and then encouraged to practise, practise, and practise' (ibid.: 211). Finally, it is stated that practice is 'especially important with the algorithms, or procedures, relating to arithmetic and computation, such as multiplication and long 
division' (ibid.: 211). In the short introductory text of around 250 words, reference is made to practice or practise on 13 separate occasions which leaves the reader with a very strong impression about the importance attached to this aspect within the Core Knowledge project.

Following the introduction, the pages that follow contain a large number of topics in mathematics under seven broad headings of numbers and numbers sense; computation; decimals, fractions and mixed numbers; ratios and probabilities; graphs, functions and word problems; geometry; and plotting lines on a grid. However, there is no clear systematic reasoning underlying this choice of categories, which do not have any clear correspondence with each other, for example the activity of 'plotting points on a grid' is not a corresponding category to the vast field of mathematical knowledge that would be held under the heading of 'geometry' for example. Nor is it clear why the topics of 'graphs and functions' are clustered together with 'word problems'. The seven broad categories are each subdivided into sub-categories, for example there are twenty-eight topics under 'decimals, fractions and mixed numbers' and overall there are ninety topics in total. However, no attempt is made at making connections across these topics. This sense of a fragmented list of disconnected topics is also reflected in the list of maths activities for Years 1 to 6 that is presented on the project website (Core Knowledge, 2018b).

On analysing the mathematical topics in the text (Hirsch, 2014) more closely there is a tendency towards a 'rule following' approach to the subject which is also combined with a loose and confusing use of language. For example, the activity related to comparing integers (ibid.: 215) makes use of a number line and results in the instruction: 'In general remember the following rules: (1) a positive integer is always greater than a negative integer and (2) the farther to the left a negative integer is from zero, the less its value is $(-1>-100) . '$ In the second example related to adding integers, the use of the number line actually confuses the issue and results in the quite incomprehensible explanation that 'You can add two negative integers the same way you add two positive integers, but because you are moving in the opposite direction, the sum is negative.' This is followed by two quite random and uninteresting rules to be remembered as follows: (1) the sum of two positive integers is positive and (2) the sum of two negative integers is negative.

In evaluating the epistemic quality of the mathematical content of what Core Knowledge aims to impart, three aspects are foregrounded. First, there is a very strong emphasis placed on practice, second a disconnected and fragmented view of the subject is presented, and third, there is a tendency towards rule following and to reducing standard procedures simply to rule following. With regard to the first aspect and taking the resulting didactical/teaching and learning situation as a point of departure, the knowledge to be imparted is encapsulated in the didactical situation (Chevallard, 2007). Accordingly, the experiences of pupils who are faced with a series of situations in which they simply 'practise, practise and practise' are likely to consist almost entirely of the mutated version of mathematics that is made up of the degraded, low epistemic quality referred to earlier. Then, the disconnected and fragmented version of the subject will be the one experienced by pupils in these situations. The presentation of mathematics simply as a list of disconnected topics as they go through the teaching and learning situations will result in a very narrow experience of the nature of the subject by pupils. The almost total emphasis on 'knowing that' in Core Knowledge represents a blind spot in relation to mathematical 'know how' and in particular to procedural and inferential know how. Finally, in relation to the tendency towards rule following, and to reducing standard procedures to rule 
following, such an approach is likely to serve to reinforce imitative, memorized and algorithmic reasoning, as described earlier, and result in mathematical knowledge of low epistemic quality.

\section{On the role of teachers as curriculum makers}

The final line of argument in this article focuses on the role of teachers. It supports Lambert and Biddulph's proposition that 'the process of curriculum making is a signature part' of a teacher's identity. Drawing inspiration from Hart (2001), who emphasizes that education is a process of transformation and evolution, they go on to highlight the complexity of the teacher's role:

In essence, it requires teachers to hold in balance three interrelated priorities: the needs, prior knowledge and experiences of students; the nature and purposes of the discipline; plus the understanding and performative craft of pedagogic technique. Curriculum making is in effect curriculum thinking in practical action, taking on a 'trinity of educational practice': subject, child, and teacher. (Lambert and Biddulph, 2015: 217)

This line of argument resonates strongly with that made by Hudson (2002, 2016b) concerning the Continental European tradition of didactics. This argues that the aspect of 'holding complexity' is a central part of a teacher's reflective practice and also highlights that it is at the classroom level that curriculum and pedagogy merge (Hudson, 2002: 53). In reflecting on the teachers' experience of being involved in the DMTPC project, Hudson (2016b) notes that it provided an opportunity for the course participants to engage in a collective process of 'didactic analysis' (ibid.). Although the teachers recognized the complexity of the teaching/studying/learning process, they paid particular attention to the studying aspect, that is, those key functions that need to be fulfilled in order to achieve the goal/end point of the process. Essentially this was achieved through auditing their current practice and undertaking a process of action research planning. Examples of other DMTPC research projects included investigations that:

- focused on meeting the challenges of mixed ability mathematics classes

- looked into the use of non-commercial resources to develop children's mathematical thinking

- promoted open-ended activities and encouraged collaborative talk with 7 to 8 year olds

- used real life mathematics in the everyday teaching of the subject to engage and develop mathematical thinking

- carried out open-ended investigations in mathematics and used a variety of media to communicate mathematical solutions and ideas

- used questioning to extend the mathematical thinking of infants and increase the children's ability to decompose and recompose numbers

- explored proofs with Primary 2 to develop mathematical thinking

- explored the impact of teacher's questioning skills on pupils' mathematical thinking.

The teachers involved in the project had all hoped to gain new ideas and develop their understanding of new methods. They expressed a desire to have the confidence to try out new methods and not rely on textbooks. While there was a certain amount of trepidation among the teachers at the start of the course, they were highly motivated 
by the challenge and saw both the course and the Curriculum for Excellence reform in Scotland as an opportunity to try out new and creative approaches to teaching mathematics. There was a general desire to 'make a difference' in terms of helping children to understand and enjoy mathematics. Findings from this study highlight the fact that the course had a transformational and emancipatory impact on these teachers (Hudson et al., 2015).

With regard to the role of the teacher, there are strong parallels between the Curriculum for Excellence reform in Scotland and the tradition of didactics in terms of the way it provides a framework that places the teacher, and not specified content and methods, at the heart of the teaching/studying/learning process. This is reflected in the fact that the success of Curriculum for Excellence is dependent on teachers taking greater responsibility to lead its development.

\section{Discussion}

This article has aimed to contribute to current debates on progressive, knowledgebased approaches to the curriculum by addressing the question of what students have an entitlement to learn in school mathematics, in particular. From the outset it recognized progressive arguments for teaching to be reconnected with the emancipatory ambitions of education. In doing so, it took the notion of powerful knowledge as a starting point, which was introduced by Young (2009) as a curriculum principle underpinning the Future 3 model. He argues for the entitlement of every pupil to have access to knowledge that is 'better, more reliable and nearer to the truth about the world we live in and to what it is to be human' (ibid.: 107). In turn, this article has considered this as a question of epistemic quality which, as a concept, is founded on the analysis of a distinction between mathematical fallibilism and mathematical fundamentalism which has been developed in the field of subject didactics. The relation between powerful knowledge and epistemic quality has been considered further by framing it within a sociological theory of knowledge. This has helped to highlight a further distinction between knowing that and knowing how, and this distinction has been used to illustrate examples of high and low epistemic quality in school mathematics.

The first example - that of high epistemic quality - was drawn from Anna's action research project 'The rainforest', part of the DMTPC project, which illustrated how mathematical thinking and the associated processes of creative reasoning are central to such know how in school mathematics. Reflecting on this example highlights the way in which processes of creative reasoning are central to procedural know how in particular. Furthermore, it is argued that such creativity needs to be recognized as an orientation, or disposition towards, mathematical activity at the outset of planning to teach and that it is something that can be fostered broadly in schools across all subjects. However, sufficient time needs to be given to the development of such creativity in school mathematics, central to which is learning from errors and mistakes and - last but not least - taking the time to think mathematically.

The second example is of low epistemic quality and is drawn from the highly promoted Core Knowledge Foundation which has recently been imported into English schools from the USA. This illustrates an overemphasis on practice, presents a fragmented view of the subject and reduces standard procedures to simple rule following. An examination of this second example highlights the need for there to be a robust national system of quality assurance over the process of curriculum development in England. This should represent all key stakeholders, including subject 
associations, disciplines and subject didactics (see further discussion below). Its focus should be on developing quality standards and a system for ensuring that resources meet the highest standards of epistemic quality.

Finally, the article has considered the role of teachers as curriculum makers in these processes at the classroom level where curriculum and pedagogy effectively merge. Findings from the DMTPC project echo the argument presented by Lambert and Biddulph (2015) that the process of curriculum making is a signature part of a teacher's identity. They argue further and that curriculum making is curriculum thinking in practice, taking on the trinity of educational practice that involves subject, child and teacher. Furthermore, they resonate with approaches reflected in the Continental European tradition of didactics which involves upholding the complexity of the trinity and recognizing that curriculum and pedagogy merge at the classroom level through a process of 'didactization' (see Gericke et al. in this special feature).

The thinking that underpins major aspects of this article owes much to research and scholarship in the field of subject didactics in mathematics in particular. The importance of subject-specific knowledge in education has been recognized through support for the development of the field of subject didactics as a research-based discipline in subject-specific fields in recent years in Scandinavia, Germany and French-speaking countries especially. In contrast, the field of subject didactics has been increasingly marginalized in the UK during that time. The significance of this field represents a blind spot for policymakers in England but is also overlooked by Young (2013) in his proposal of powerful knowledge. This concept is based on the recognition of the boundaries between disciplines and subjects which define their focus and objects of study. Furthermore, it explicitly locates knowledge in the specialist communities of researchers in different fields and, consequently, does not treat knowledge as given but as fallible and open to challenge through dialogue and debate within those communities. Accordingly, knowledge under Future 3 is bounded by the epistemic rules of the particular specialist communities. However, in arguing that Future 3 should treat subjects as the most reliable tools that have been developed for enabling students to acquire knowledge and make sense of the world, Young (ibid.) overlooks the crucial role of subject didactics. In this article, it is argued that a major role of subject didactics is to research the boundary between disciplines and school subjects, and to develop knowledge about the processes of transformation associated with them in partnership with university disciplines and subject associations. A considered contribution to this role and proposed direction for future research in subject didactics on powerful knowledge across school subjects is presented by Gericke et al. in this special feature.

\section{Acknowledgements}

I wish to thank the two anonymous referees and also David Lambert, the editor of this special feature, for their very constructive feedback on an early version of this article.

\section{Notes on the contributor}

Brian Hudson is Professor of Education and former Head of the School of Education and Social Work at the University of Sussex, guest professor at Karlstad University and honorary professor at the University of Dundee. He is a Fellow of the Institute of Mathematics and its Applications, an honorary member of EERA Network 27 Didactics - Learning and Teaching and was awarded a National Teaching Fellowship in 2004. 
His main research interests are in mathematics education, ICT and learning and comparative curriculum studies.

\section{References}

Biesta, G.J.J. (2010) Good Education in an Age of Measurement: Ethics, politics, democracy. Boulder, CO: Paradigm Publishers.

Biesta, G.J.J. (2012) 'Giving teaching back to education: Responding to the disappearance of the teacher'. Phenomenology and Practice, 6 (2), 35-49.

Biesta, G.J.J. (2017) The Rediscovery of Teaching. London: Routledge.

Boaler, J. (2009) The Elephant in the Classroom: Helping children learn and love maths. London: Souvenir Press.

Brousseau, G. (1997) Theory of Didactical Situations in Mathematics: Didactique des mathématiques, 1970-1990. Dordrecht: Kluwer Academic.

Chevallard, Y. (2007) 'Readjusting didactics to a changing epistemology'. European Educational Research Journal, 6 (2), 131-4.

Chevallard, Y. and Johsua, M.-A. (1991) La transposition didactique: Du savoir savant au savoir enseigné. 2nd ed. Grenoble: La Pensée sauvage.

Core Knowledge (2018a) 'What Your Child Needs to Know'. Online. www.coreknowledge.org.uk/ books.php (accessed 18 July 2018).

Core Knowledge (2018b) 'Maths activities'. Online. www.coreknowledge.org.uk/maths.php (accessed 18 July 2018).

du Plooy, L. and Zilindile, M. (2014) 'Problematising the concept epistemological access with regard to foundation phase education towards quality schooling'. South African Journal of Childhood Education, 4 (1), 187-201.

Gericke, N., Hudson, B., Olin-Scheller, C. and Stolare, M. (2018) 'Powerful knowledge, transformations and the need for empirical studies across school subjects'. London Review of Education, 16 (3), 428-44.

Hart, T. (2001) From Information to Transformation: Education for the evolution of consciousness (Counterpoints 162). New York: Peter Lang.

Hirsch, E.D. (ed.) (2014) What Your Year 6 Child Needs to Know: Fundamentals of a good Year 6 education. London: Civitas.

Hudson, B. (2002) 'Holding complexity and searching for meaning: Teaching as reflective practice'. Journal of Curriculum Studies, 34 (1), 43-57.

Hudson, B. (2015) 'Butterflies and moths in the Amazon: Developing mathematical thinking through the rainforest'. Éducation et Didactique, 9 (2), 119-33.

Hudson, B. (2016a) 'Boredom, alienation and anxiety in the maths classroom? Here's why'. The Conversation, 1 December. Online. http://theconversation.com/boredom-alienation-andanxiety-in-the-maths-classroom-heres-why-69570 (accessed 18 July 2018).

Hudson, B. (2016b) 'Didactics'. In Wyse, D., Hayward, L. and Pandya, J. (eds) The SAGE Handbook of Curriculum, Pedagogy and Assessment. London: SAGE Publications, 107-24.

Hudson, B. (2017) 'Epistemic quality for inclusive and equitable mathematics education for all'. Paper presented at the World Education Research Association (WERA) Focal Meeting and Hong Kong Education Research Association (HKERA) International Conference, Education University of Hong Kong, 30 November-2 December 2017.

Hudson, B., Henderson, S. and Hudson, A. (2015) 'Developing mathematical thinking in the primary classroom: Liberating students and teachers as learners of mathematics'. Journal of Curriculum Studies, 47 (3), 374-98.

Lakatos, I. (1976) Proofs and Refutations. Cambridge: Cambridge University Press.

Lambert, D. and Biddulph, M. (2015) 'The dialogic space offered by curriculum-making in the process of learning to teach, and the creation of a progressive knowledge-led curriculum'. AsiaPacific Journal of Teacher Education, 43 (3), 210-24.

Lithner, J. (2008) 'A research framework for creative and imitative reasoning'. Educational Studies in Mathematics, 67 (3), 255-76.

Morrow, W. (2009) Bounds of Democracy: Epistemological access in higher education. Cape Town: Human Sciences Research Council Press.

Muller, J. (2016) 'Knowledge and the curriculum in the sociology of knowledge'. In Wyse, D., Hayward, L. and Pandya, J. (eds) The SAGE Handbook of Curriculum, Pedagogy and Assessment. London: SAGE Publications, 92-106. 
NCTM (National Council of Teachers of Mathematics) (2000) Principles and Standards for School Mathematics. Reston, VA: National Council of Teachers of Mathematics.

OECD (Organisation for Economic Co-operation and Development) (2007) Quality and Equity of Schooling in Scotland (Reviews of National Policies for Education). Paris: Organisation for Economic Co-operation and Development.

Pólya, G. (1954) Mathematics and Plausible Reasoning. Princeton: Princeton University Press.

Schneuwly, B. (2011) 'Didactic transposition: A key concept in the French tradition of "Didactiques des disciplines/Fachdidaktik"'. Paper presented at the European Conference on Educational Research (ECER), Freie Universität Berlin, 13-16 September 2011.

Schoenfeld, A.H. (1985) Mathematical Problem Solving. Orlando, FL: Academic Press.

Stenhouse, L. (1980) 'Curriculum research and the art of the teacher'. Curriculum, 1(1).

Winch, C. (2013) 'Curriculum design and epistemic ascent'. Journal of Philosophy of Education, 47 (1), 128-46.

Young, M. (2009) 'Education, globalisation and the "voice of knowledge"'. Journal of Education and Work, 22 (3), 193-204.

Young, M. (2013) 'Overcoming the crisis in curriculum theory: A knowledge-based approach'. Journal of Curriculum Studies, 45 (2), 101-18.

Young, M. (2014) 'Why start with the curriculum?'. In Young, M., Lambert, D., Roberts, C. and Roberts, M. (eds) Knowledge and the Future School: Curriculum and social justice. London: Bloomsbury Academic, 41-64.

Young, M. and Muller, J. (2010) 'Three educational scenarios for the future: Lessons from the sociology of knowledge'. European Journal of Education, 45 (1), 11-27. 